EPiC Series in Computing
Volume 69, 2020, Pages 112-121
Proceedings of 35th International Confer-
ence on Computers and Their Applications

\title{
Metrics and Indicators to evaluate the degree of transformation to Smart City of a city. An Ad-Hoc Quality Model
}

\author{
Narayan Debnath ${ }^{1}$, Mario Peralta ${ }^{2}$, Carlos Salgado ${ }^{2}$, Luis Roqué2 ${ }^{2}$, Daniel \\ Riesco $^{2}$, Germán Montejano' ${ }^{2}$, Mouna Mazzi ${ }^{3}$ \\ ${ }^{1}$ School of Computing and Information Technology \\ Eastern International University, Vietnam \\ narayan.debnath@eiu.edu.vn \\ ${ }^{2}$ Departamento de Informática Facultad de Ciencias Físico-Matemáticas y \\ Naturales Universidad Nacional de San Luis, Ejército de los Andes 950. San Luis, C.P. 5700, \\ \{mperalta, csalgado, driesco, araroq, gmonte\}@unsl.edu.ar \\ ${ }^{3}$ University Mohammed V, Avenue des Nations Unites, Rabat, 10000. \\ mazzi.mouna@gmail.com
}

\begin{abstract}
The extreme levels of intensity with which people live in large urban centers began to affect the productivity and quality of life of cities and their inhabitants, some of which have reached extremes close to collapse, as is the case of traffic congestion in the main cities of the world. On the other hand, from digital innovation and economic development, it is necessary to provide intelligent solutions to current problems, promoting the entrepreneurial ecosystem and the collaborative economy. Each government should administer, manage and update information from each region, and distribute it in the most convenient way to each company or agency that is part of a smart city. To achieve smart cities, we must train digital citizens and take into account the accessibility conditions provided by technology. For this, the implementation of Internet of Things (IoT) at all possible levels is of the utmost importance. From these points of view, mobility has become a central issue of urban development. Its relationship with sustainability issues and its ability to generate competitiveness and quality of life, puts us before the need to rethink its future. These are certain considerations to include in possible models of quality that allow to study the degree of intelligence of the cities. When talking about indicators or metrics, it begins to pose a problem of being able to generalize / extend each of these measures. In this line of research, a board of metrics and indicators has been defined that are applicable to an ad hoc quality model whose objective is to study the degree of intelligence of cities.
\end{abstract}




\section{Introduction}

Large cities have become urban centers with extreme levels of intensity, both for those who inhabit them and for those who live daily during working hours. This problem began to affect the productivity and quality of life of cities and inhabitants, some of which have reached extremes close to collapse, as is the case of traffic congestion in the main cities of the world. On the other hand, from digital innovation and economic development, it is necessary to provide intelligent solutions to current problems, promoting the entrepreneurial ecosystem and the collaborative economy for the development of publicprivate projects. An important issue to consider is that each government should administer, manage and update the data/information coming from each region/city/country, and distribute it in the most convenient way to each company or public or private organization that is part of a smart city. From another perspective, to achieve Smart Cities, we must form digital citizens and take into account the accessibility conditions provided by technology, the generation of collaborative tools designed and thought so that citizens work together with the government to resolve issues of security and prevention, augmented reality, robotics, nanotechnology, the idea of a more personalized future through 3D manufacturing and the contribution of advanced innovations by each member of worldwide societies that will allow contributions in terms of health, energy generation, etc. To this end, it is extremely important to implement the Internet of Things at all possible levels, to see a real transformation, both in business development and in everyday life, and its consequent economic and sustainable benefits for the system.

From these points of view, mobility has become a central issue in urban development. Its relationship with sustainability issues and its capacity to generate competitiveness and quality of life, places us before the need to rethink its future. To this end, we must think about a more critical approach to infrastructure and improvements in public transport services, such as arrival and frequency forecasts, a lower percentage of cancelled services, greater comfort for passengers, and wider networks, are the key to the leap in quality in intelligent mobility. These are certain considerations to be included in possible quality models that allow studying the degree of intelligence of cities. However, achieving a general quality model for intelligent cities is not so simple, since each city has different growths and is subject to its culture and idiosyncrasy. To talk about indicators or metrics, implies posing the problem of being able to generalize/extend each one of these measures.

In this research line, based on the aforementioned considerations, a table of metrics and indicators has been defined that are applicable to an ad hoc quality model whose objective is to study the degree of intelligence of cities. In this context, the smart cities can be identified and classified according to the following six main dimensions [1]:

\section{- Smart Economy}

- Smart Government
- Smart Environment

- Smart People
- Smart Living

- Smart Mobility

All urban agglomerations present different challenges. One of its challenges is to tackle the project of designing a smart city while maintaining its DNA. Each city has its own signs of identity and its own values that are expressed in architectural forms, the configuration of spaces and, above all, the relations between its inhabitants, and between citizens and their government [2]. For this reason, urban planning and the development of dynamic decision-making mechanisms that take into account the growth and inclusion of citizen participation processes are increasingly important. In this sense, transforming "traditional cities" into Smart Cities is an increasingly important demand and also an opportunity for governments and citizens to considerably improve the quality of life. With the emergence of digital technology, the Internet and mobile technologies, this transformation is increasingly viable [3].

If the analysis focuses only on mobility as the axis of a smart city, it is essential to highlight that, given the recent increase in concern for the environment and the improvement in the quality of life, as well as the interest in reducing factors that affect climate change, the use of bicycles within urbanization arises as a low-cost and non-polluting alternative in comparison with conventional means of transport. 
The concept of "urban cycling" (also called utilitarian cycling) is beginning to be integrated into urban transport systems. Smart cities have given bicycles a very special place in their transport systems, but this, in turn, has brought with it a number of implications that are not visible to the naked eye and are worth considering. One of them is that, by conceptualizing the bicycle as a means of transport, one must change the paradigm in the planning of traffic and mobility in a city, taking into account that it incorporates the use of technology, and with it the use of management software. In such a way that it is an indispensable requirement to provide a guarantee that the applications that manage the open fleets, specifically bicycles, are acceptable from the point of view of software quality. This transforms the traditional cities infrastructure into a living and sustainable ecosystem, providing benefits to the people who live and work there [4]. According to ISO 9000 [5], quality is the "degree to which a set of inherent characteristics meets the requirements". As requirements will depend on different stakeholders, quality is a multidimensional concept, as it can be synonymous with efficiency, flexibility, correctness, reliability, ease of maintenance, portability, ease of use, security, integrity, etc. In the evolution experienced by the quality of computer systems, there has been a shift from a treatment focused fundamentally on the inspection and detection of errors in the programs, to a more systematic approach, given the importance that quality has acquired in systems engineering and software engineering. The demand for software by organizations and society in general has grown much faster than the industry's capacity to produce quality software, chronicling the so-called "software crisis" [6].

One of the main reasons for the massive increase in interest in software metrics, has been the perception that they are necessary to improve the quality of the process [7]. In order to ensure that a process or its resulting products are of quality, or to be able to compare them, it is necessary to assign values, descriptors, indicators or some other mechanism by which this comparison can be carried out. For this, it is necessary to carry out a software measurement process that, in general, pursues three fundamental objectives: to help understand what happens during development and maintenance, to control what happens in projects and to be able to improve processes and products [8]. Indeed, metrics are a good way to understand, monitor, control, predict and test software development and maintenance projects [9], and can be used by professionals and researchers to make better decisions.

Fenton and Pfleeger [8] define measurement as: "the process of assigning numbers or symbols to the attributes of real-world entities so that they can be described according to clearly defined rules". Some relevant aspects to consider in the context of measurement theory applied to software measurement are the following: Scale. The Scales allow establishing the most appropriate type of representation for an attribute, so that their values can be compared. Considering that different scales can measure the same attribute, an important question to ask is which scale is most appropriate in each case. Internal and external attributes. Internal attributes are those attributes of an entity that can be measured without the need to evaluate the external behavior of that entity. External attributes are measurements of how an entity is related to the environment. Direct and indirect measurements. A direct measurement is the measurement of an attribute of an entity without being other entities involved. Indirect measurements require other attributes.

\section{Research Lines and Development and Innovation}

An important point when analyzing a Smart City is its value system or chain. The value chain of a Smart City is a model that allows describing the different activities and phases through which the agents involved in the ecosystem of a city must go through to transform it into a smart city [10]. The need to break the digital gap and to extend new communication technologies to all corners of cities is a challenge for companies and governments that have to work together to realize the trends that will make it possible for all of us to be connected, improve the fiber-optic network of cities and consolidate a fundamental conjunction, that is, connectivity will be a key element for future development [11]. Urban 
agglomeration, in rapid expansion, centralizes economic and administrative functions at the local level, that is, municipalities, and increases social problems such as congestion, pollution and social inequalities [12]. In this scenario, the concept of "smart cities", although popularized, is a complex term that has different definitions and an interdisciplinary nature $[13,14]$.

In this work, the technological dimension of a smart city will be adopted, since there are other dimensions such as human and institutional [13]. According to Angelidou [14], smart cities use technology in a conscious and planned way to placate urban problems. The literature highlights the use of ICT as an ally to solve urban problems such as air pollution, congestion and waste management [14, $15,16,17]$. ICTs would be the central nervous system of an interconnected city, which allows obtaining data from different sources (sensors) to achieve the concept of meaning and act, that is, alarm and action. The information collected by the devices can be correlated, analyzed and then used to create planning and control processes that improve productivity and assertiveness in decision making by public managers [18]. Within this framework, the United Nations [19] points out that it is necessary for a smart city model to consider all aspects of a sustainable city, with an integrating vision that takes into account people and not just technology as an essential part of its own development, working on an intelligent sustainable city that relies on the technological means that come along with the fourth industrial revolution. However, it should be noted that a recent study comparing measurement indicators between a sustainable city and a smart city [17], suggests that the second model does not solve most of the problems represented by the environmental pillar, which is due to its mostly socio-economic approach and the environmental cost generated by new technologies in global development.

Based on the expressed, this research work arises as a necessity in regards to a request for development, in a first stage, of smart garbage dumps or smart garbage collection in a municipality in the province of San Luis - Argentina. When meeting with stakeholders we are required to advise on a larger and more ambitious project, which aims to turn the municipality into a smart city. In this context, a line of research on smart cities focused on quality aspects is being developed. Among the works that have been carried out, we can mention the definition of a mixed quality model, for responsible software for the dynamic coordination management of open fleets (specifically bicycles) in a smart city, based on an engineering approach to measure and evaluate the quality of a software product [20]. Along the same lines, we are currently working on the development of a tool to automate the measurement and evaluation of the quality of web-mobile applications for this type of fleet [21], based on a Quality Model whose pillar is the ISO 25000 product quality standard [22]. Thus, in this work, a board of metrics and indicators are presented that are applicable to an ad-hoc quality model whose objective is to study the degree of intelligences of the cities [23, 24, 25]. By the above, it is necessary to define a quality model that serves as a guide to start moving towards a smart city. To measure various indicators were used in each of the dimensions concerning smart cities. The "Smart" Methodology, proposed in [26, 27], defines a set of criteria in which 60 indicators are established divided into 5 clusters. Many of these indicators will be considered and redefined or adapted to the reality of the problem when applying the proposed ad-hoc quality model.

In the following section, the proposed quality model is presented.

\section{Quality Model}

The proposed quality model is divided into 5 main categories of characteristics desirable to users. These categories are subdivided into sub-characteristics as show in Figure 1.

The following is a definition of the characteristics that compose the proposed quality model.

Business and Energy: At this point, a range of possibilities opens up, among which are the optimization of energy sources and an equitable distribution of them. Energy should be distributed between the company, citizens and the government. Data/information capture instruments should enable 
governments to intelligently manage these data/information and transmit the data/information analyses to energy distribution companies so that they have control over the availability of natural light across a country, region or continent. This will result in an improvement in the consumption and control of available energy. At this point a small change will be made to have an energy efficiency.

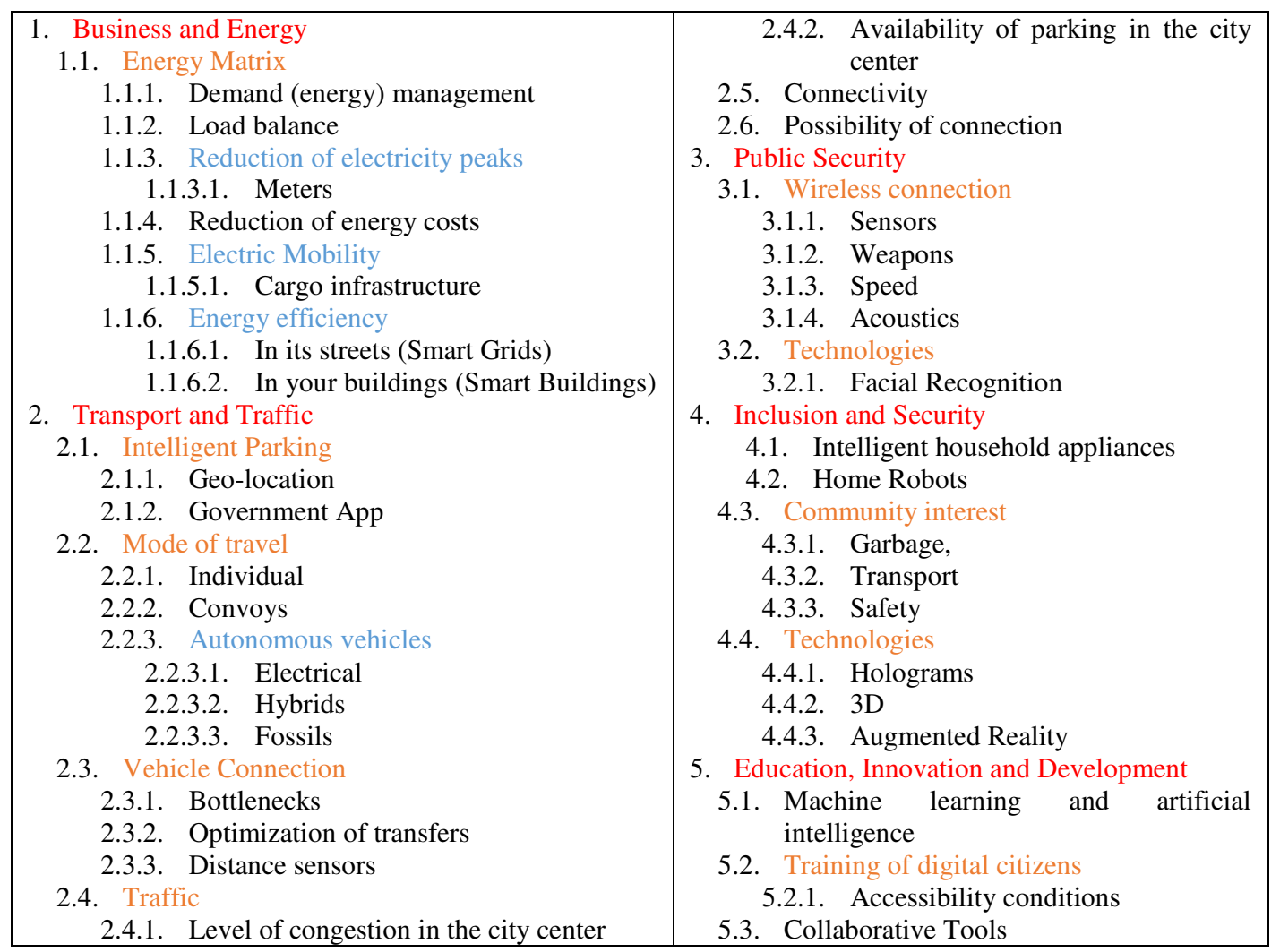

Figure 1: Quality Model to Smart City

Transport and Traffic: Mobility has become a central issue in urban development. Its relationship with sustainability issues and its capacity to generate competitiveness and quality of life, place us before the need to rethink its future. It is necessary to think about improvements in infrastructure and public transport services, such as arrival and frequency forecasts, a lower percentage of cancelled services, etc., which are the key to the quality leap in intelligent mobility. Consideration should be given to efficient routes, similar to the subway networks of the world, for the mobilization of private cars, passenger transport, etc. The next generation of cars will communicate and will be able to relate to other vehicles on the road, looking around corners and even through trucks. Traffic signals and interactive traffic lights equipped with sensors will also communicate with each other and exchange information with the vehicles in the area. Even you will be able find a free parking space. Succeeding in making traffic more fluid will improve mobility. This also has an impact on the environment. At this point, doubts arise as to safety, that is to say, whether vehicle data and information will be safe, or it will be possible to track each one of them. Will there be a violation of privacy? Data is not stored anywhere and users do not have to worry about the implications for their private life, according to Ilja Radusch, from "We use pseudonyms Institute", "Instead of an identity, each vehicle has a thousand identities that change every second. So no one can track you".

Public Security: The infrastructure of networks and communications through the Internet is of priority 
importance to think about the creation of health networks, safety networks through facial recognition, etc., to digitize public hospitals, police stations, airport / maritime police, among others. In addition to networks and sensors, a "smart city" must use software to take advantage of this data. The installation of different types devices to collect data, information and knowledge will be crucial, and store it in the cloud. Information capture instruments should enable governments to intelligently manage such information and transmit their analysis to companies or government departments.

Inclusion and Security: Infrastructure is the backbone for the new Smart City paradigm. It is essential to have a scalable and robust infrastructure that allows adaptation to the changes that will come. The fifth generation of mobile broadband promises to give the necessary impetus so that access to the network of networks is available to connect any kind of objects in the so-called Internet of things (IoT). The 5G connection will enable a world of intelligent, interconnected cities, remote robotic surgery and immersion in the IoT. This scenario is very close, as scientists, governments and communications companies make plans to start using 5G from 2020. This fifth generation would allow speeds of 10 Gbps to be reached. This new technology will not only allow a higher connection speed, but will also be able to support up to 100 times more connected. It would also reduce power consumption, extend battery life, which will contribute to the environment and the ecosystem.

Education, Innovation and Development: To achieve smart cities, we must form digital citizens and take into account the accessibility conditions that technology can provide. With regard to technology, for example, we can consider: augmented reality, robotics, nanotechnology, the idea of a more personalized future through 3D manufacturing and the contribution of advanced innovations by each member of societies worldwide that will allow contributions in terms of health, energy generation, etc. The generation of collaborative tools designed and thought so that the citizens work together with the government in solving issues of security and its prevention, implies that the institutions must think in periodic trainings of update and improvement in these types of tools, and have teams of investigation on collaborative issues that contribute to the good interaction between citizens and institutions.

Metrics and Indicators: The proposed quality model is accompanied by a set of defined metrics, redefined and/or adapted from the bibliography, so that they are applicable to the domain of the problem, which specific to a region of a country. In addition, different indicators have been defined that allow an interpretation of the measurements that are made through the different metrics. Below is a summary of some of the metrics:

Metrics:

\#NWA: Number of WIFI Antennas.

P4gA: Percentage of 4G Antennas.

SC: Speed of Connection.

PSP: Percentage of Solar Panels.

\#NLL: Number of Led Luminaires.

\#NB: Number of Bicycles.

PB: Percentage of Bicycles.

\#NIGC: Number of Intelligent Garbage Containers.

\#NIIS: Number of Intelligent Interrelated Systems.

\#NOpGPS: Number of Optimized GPS.

\#NSD: Number of State Drones.

\#NMP: Number of Meteorological Plants.

\#NHG: Number of Household Generators.

DIGA: Degree of Interconnection of Government Applications.

DGC: Degree of Garbage Collection/Classification.

Together with the previously presented metrics, an indicator was defined for each of them. As an example, one of them is presented:

Indicator: CE: Connection Efficiency
\[ \mathrm{CE}(\mathrm{SC})=\left\{\begin{array}{cl}0,2 & \text { Metric: } \mathrm{SC}=\text { Speed of Connection. } \\ 0,4 & 1 \mathrm{Mbps}<=\mathrm{SC}<=10 \mathrm{Mbps} \\ 0,5 & 12 \mathrm{Mbps}<\mathrm{SC}<=16 \mathrm{Mbps} \\ 0,6 & 16 \mathrm{Mbps}<=\mathrm{SC}<=99 \mathrm{Mbps} \\ 0,7 & 100 \mathrm{Mbps}<=\mathrm{SC}<=200 \mathrm{Mbps} \\ 0,8 & 150 \mathrm{Mbps}<\mathrm{SC}<=200 \mathrm{Mbps} \\ 1 & 200 \mathrm{Mbps}<\mathrm{SC}<=1000 \mathrm{Mbps}\end{array}\right. \]




\section{Case Study: Integral Modernization Program}

A Municipality of the province of San Luis, Argentina, has established as its objective to achieve a profile of Smart City, in order to place the municipality at the height of the most dynamic cities in the world. This is a very ambitious objective with unquestionable potential benefits for the entire municipality, which requires a deep feasibility analysis to determine, in terms of a cost/benefit ratio and a scheme of priorities, what is effectively convenient for the municipality and which is the appropriate strategy for the proposal to be successfully developed. The proposal implies, in the different dimensions (definition of strategies and derivatives, technological resources, human resources, professional resources, development and implementation efforts, etc.) inherent to projects of this magnitude, a level of efforts proportional to the ambitious objectives set. For example, a project of this nature must necessarily begin with a cultural analysis of the entire municipality, in order to determine the cultural change and the necessary strategies for, by defining the remaining components, establishing strategic and operational plans that lead to the achievement of the different objectives. That is, to carry out this proposal implies the definition of a long-range macro-project with the participation of multidisciplinary teams in charge of activities such as:

Feasibility analysis of the proposal in the municipality: Analysis of the current situation of the municipality, its vision of the future, determining what the municipality needs to move towards that vision of the future and what part(s) or aspect(s) of the proposal are consistent with that vision of the future, for example: If the municipality needs to asphalt its streets or build a sewage system, in what order of priority are components of the proposal located with respect to those needs?

Formulation (or reformulation) of the strategic direction of the municipality: Consistent with the results of the feasibility analysis: (i) Formulation (or reformulation) of the mission, vision and strategic objectives of the municipality. (ii) Formulation of a global strategy to advance towards the formulated strategic objectives. (iii) Formulation of strategic lines within the framework of the global strategy. (iv) Formulation of strategic projects within the framework of each strategic initiative.

Formulation of operational projects: Within the framework of strategic projects and initiatives, formulation of projects (with planning and allocation of resources involved) with the objective of carrying out parts and aspects of the original proposal within the framework of strategies and feasibility determined for the municipality.

In order to carry out the project, several professional profiles are required. It is necessary to have computer engineers and network technicians for everything related to the underlying infrastructure to run the software. As part of the feasibility studies, in terms of infrastructure, the proposed quality model was instantiated and the evaluation was carried out to produce reports so that the appropriate strategies and planning are prepared to carry out the long transition to a city of the future.

An example of what we have worked on refers to evaluating the smart parking of the city, characteristic 2 of the quality model used. Below is a summary of its instantiation:

a) Need for Information: To evaluate the degree of intelligence of a city.

b) Calculable concept: Intelligence.

c) Entity: The City. In this case the municipality.

d) Quality Model or Concept Model (Characteristics taken from the model proposed)

1 Traffic

1.1 Level of congestion in the city center.

1.2 Availability of parking in the city center.

2 Connectivity

2.1 Possibility of Connection.

\section{e) Calculable Attributes}

a. Number of vehicles in circulation in the city center. d. Total number of vehicles.

b. Number of parking places.

c. Number of Access Points (AP) available.

e. Total number of parking places.

f. Total number of AP. 


\section{f) Metrics}

a. Directs

1. \#NVD: Number of vehicles driving through a strategic point in the city center per minute.

2. \#TNV: Total number of vehicles (estimated).

3. \#NED: Number of empty docks (supposed: parking in the city center is exclusively in paid docks).

4. \#TND: Total number of docks.

5. \#NAAP: Number of available Access Points (AP) (those running on and not saturated).

6. \#TNAP: Total Number of AP.

b. Indirect

1.PFP: Percentage of free parking. It can be calculated as the number of empty docks divided by the number of docks and at this value multiply by one hundred.

2.PAC: Percentage of available connection. It can be calculated as the number of available AP divided by the total number of AP and at this value multiplied by one hundred.

c. Scales: For metrics 1 to 6 the scale is absolute and the units are vehicles for 1 and 2, docks for 3 and 4 , and access points (AP) for 5 and 6. For the metric PFP, the scale is proportion (from 0 to 100). For the metric PAC, the scale is ratio (from 0 to 100).

\section{g) Indicators}

a. Elemental Indicators (EIx)

EI1 = TCC (Traffic in the City Center).

$$
\mathrm{TCC}(\# \mathrm{NVD})= \begin{cases}0=\text { High } & \text { if \#NVD }>=X \max \\ 1=\text { Low } & \text { if \#NVD }<=X \min \end{cases}
$$

EI2 $=$ FPCC (Free Parking in the City Center)

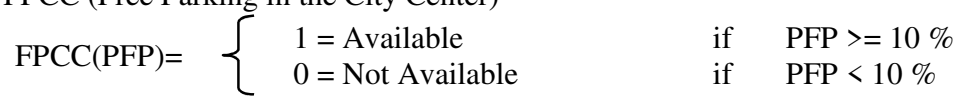

EI3 = PIC (Possibility of internet connection)

\section{b. Global Indicator (GI)}

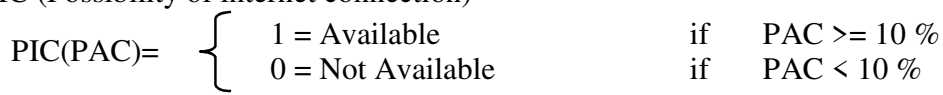

$\mathbf{G I}=0.25 \times \mathrm{EI} 1+0.25 \times \mathrm{EI} 2+0.5 \times \mathrm{EI} 3$

The same weight is given to Traffic (EI1 and EI2 with 0.5 between both) and Connectivity (EI3 = 0.5).

\begin{tabular}{|c|c|c|}
\hline $\begin{array}{c}\text { Metric } \\
\text { s }\end{array}$ & Measurement & Suggestions/Recommendations \\
\hline $\begin{array}{l}\text { P4gA } \\
\text { P5gA }\end{array}$ & $\begin{array}{l}\text { P4gA }=85 \% \\
\text { P5gA=0 }\end{array}$ & $\begin{array}{l}\text { Low transmission speed for autonomous vehicle control. } \\
\text { Technology update. }\end{array}$ \\
\hline DIGA & DIGA = 2 & $\begin{array}{l}\text { Standardization of data is recommended. Application of standards such as ISO } \\
25012 \text {, and migration of applications to more current technologies for scalability } \\
\text { purposes. }\end{array}$ \\
\hline DGC & DGC $=2$ & $\begin{array}{l}\text { Applications are needed to inform the neighbors the time to take out the different } \\
\text { packages with classified garbage. Training courses on the use of applications are } \\
\text { recommended for better awareness. }\end{array}$ \\
\hline PLL & PLL $=89 \%$ & It is recommended to conclude with the replacement of old lamps. \\
\hline
\end{tabular}

Similarly, the characteristics of the proposed quality model have been evaluated through the use of the metrics and indicators proposed in this research work. Table 1 show some results obtained.

Table 1: Some results obtained

As we described at the beginning of this section, the main key of the challenge lay in the execution of the first phase of feasibility study and formulation of the strategic direction of the municipality. This was so because it was necessary to balance the initiative of the municipality with its reality and projection. The activities of this first phase, implied the need for a preparation effort that involved, among other activities, the formation of a mixed team made up of resources managed by the municipality, such as a project leader with knowledge of the government area, technology and the smart city concept, technical teams specialized in development, software updates and communications 
technology and resources provided by the National University of San Luis. It should be noted that the municipality had already taken a first step towards smart cities by constructing an intelligent building for the Municipality, which, among other things, has a geothermal cooling system, self-sustaining green terraces, etc.

\section{Conclusions}

Infrastructure is the backbone for the new Smart City paradigm. It is essential to have a scalable and robust infrastructure. With the feasibility studies and the developed appropriate strategies and planning, the proposal presents many important advantages for the community in general: (i) A significant number of developments to involve students and software professionals in the area of influence. (ii) An important possibility that the involved students/individuals acquire an important experience in an interesting area and with a lot of projection towards the future. (iii) An important possibility of work for students who graduate from the career, either because they continue participating in the projects of the municipality or because of the experience they acquire in an area of great projection. (iv) A concrete possibility of extension for the UNSL. (v) Prestige and experience for the UNSL for the contribution and participation in eventually successful projects of the environment.

At this stage of the project, decisions have been made in the conformation of the technical teams integrated by personnel from different experiences. The final year students of Technicature, Bachelor and Engineering in computer science have been involved only at the level of operational projects with specific development objectives and compatible with the requirements of the projects. That is, only at the levels of operational projects, with responsibility in the development of functional aspects. It should be clarified that, although carrying out smart city projects are very expensive, the recovery in the medium and long term largely justify the investment, since it will result in substantial savings in several sectors such as energy consumption, cleaning, prevention and Security, among others.

In addition to the benefits of a smart city, this project allowed the development of a case of experimentation for the evaluation of the quality model proposed. For this, a board of metrics and indicators applicable to an ad hoc quality model was defined in order to study the degree of intelligence of cities. The degree of concordance of the set of metrics and indicators included in the board with aspects of the smart city project, made the board a tool of great importance for other purposes such as: Preparation, communication and justification of the recommendations in the feasibility study process. Here, the scheme of metrics and indicators was used: (i) As a complementary guide in the feasibility study on the way to becoming a smart city; (ii) As a complementary template for the specification of recommendations as a function between the states described; (iii) As a documentary backing of the recommendations made. Formulation of the strategic direction of the municipality and formulation of strategies, plans and strategic and operational projects of the project. This activity, was based mainly on the results of the feasibility study and here also the set of metrics and indicators included in the board was very useful fulfilling an essential role. In this case, given that the set of metrics and indicators of the board was used as a complementary guide for the study, its information was fundamental acting as a complementary support for the elaboration of the components of the strategic directionality of the municipality. The formulation of strategies, plans and strategic and operational projects of the project, in the same way as in the case of the formulation of the strategic direction of the municipality, for this activity the results were essential for the set of metrics and indicators of the board obtained during the feasibility study. In this case, the specification of recommendations as a function between the present and recommended states, together with the complementary support based on values of metrics and indicators, also constituted a very valuable complementary basis for the formulation of strategies, plans and strategic and operational projects of the project.

In conclusion of the experience so far, we can confirm the validity and utilities of the metrics and 
indicators used and we have obtained a significant amount of information for the extension and refinement of the model. Our intention is to increase and refine the proposed model with the results of the experience and apply it successively in the project in another variety of activities.

\section{References}

[1] U. d. Alicante. Smart City. Available: https://web.ua.es/es/smart/ambitos-smart-university.html, 2016

[2] E. Martin, "Economía Digital," 2017.

[3] M. Bouskela, M. Casseb, S. Bassi, C. De Luca, and M. Facchina, "La ruta hacia las smart cities: Migrando de una gestión tradicional a la ciudad inteligente," Banco Interamericano de Desarrollo DB-MG-454, 2016, Available: $\quad$ https://publications.iadb.org/publications/spanish/document/La-ruta-hacia-las-smart-citiesMigrando-de-una-gesti\%C3\%B3n-tradicional-a-la-ciudad-inteligente.pdf.

[4] T. Marin, "El transporte en bicicletas de las Ciudades Inteligentes," 2015, Available: http://thesmartcitizenproject.cl/el-transporte-en-bicicletas-de-las-ciudades-inteligentes/.

[5] UNE-EN ISO 9000:2000. Sistemas de gestión de la calidad Fundamentos y vocabulario., 2000.

[6] M. G. Piattini Velthuis, F. O. García Rubio, and I. Caballero, Calidad de Sistemas de Informáticos. 2007.

[7] N. Fenton, "Viewpoint Article: Conducting and Presenting Empirical Software Engineering," Empirical Software Engineering, vol. 6, no. 3, pp. 195-200, 2001.

[8] N. Fenton and S. L. Pfleeger, Software Metrics: A Rigorous and Practical Approach". Ed: PWS PUBLISHING COMPANY. Boston, MA, USA: PWS Publishing Co., 1997.

[9] L. Briand, S. Morasca, and V. R. Basili, "Property-Based Software Engineering Measurement," IEEE Transactions on Software Engineering, vol. 22, pp. 68-86, 1996.

[10] D. Sikora - Fernández, "Factores de desarrollo de las ciudades inteligentes," Revista Universitaria de Geografía, vol. 26, 2017.

[11] P. Quezada, L. Enciso, and J. Garbajosa, "Using tools of cloud computing for defining, planning, monitoring innovation projects and knowledge generation " in XI JIISIC 2015, pp. 121-131.

[12] H. M. Kim and S. S. Han, "City profile Seoul," Cities (London, England), vol. 29, p. 13, 2012.

[13] T. Nam and T. A. Pardo, "Conceptualizing Smart City with Dimensions of Technology, People, and Institutions," in 12th Annual International Conference on Digital Government Research, New York, 2011.

[14] M. Angelidou, "Smart city policies: A spatial approach. ," Cities: The International Journal of Urban Policy and Planning, vol. 41, no. p.S3-S1, 2014.

[15] A. Caragliu, C. Del Bo, and P. Nijkamp, "Smart Cities in Europe," Journal of Urban Technology, 2011.

[16] A. Zanella and e. al., "Internet of Things for Smart Cities," IEE Internet of Things Journal, 2014.

[17] H. Ahvenniemi and e. al., "What are the differences between sustainable and smart cities?," Cities (London, England), vol. 60, p. 234, 2017.

[18] P. Neirotti and e. al., "Current trends in Smart City initiatives: Some stylised facts," Cities, vol. 38, 2014.

[19] A. Kassim, A. Jaidka, el al., "Un-Habitat Global Activities Report 2015. Increasing Synergy for Greater National Ownership," in "Settlements Programme (UN-Habitat)," UNO.

[20] A. R. Rivoira, el al., "Modelo de calidad mixto para software responsable de la gestión de la movilidad urbana en Smart Cities," in VI CoNaIISI, Mar del Plata, Argentina, 2018: Editorial UTecNe.

[21] G. Cavallera, et al., "Un Método para Medir la Calidad de Sistemas de Gestión del Tráfico para Flotas Dinámicas en una Ciudad Inteligente," in VI CoNaIISI, Mar del Plata, Argentina, 2018: Editorial UTecNe.

[22] ISO/IEC 25000. SQuaRE - System and Software Quality Requirements and Evaluation.

[23] M. Peralta, C. Salgado, et al., "Un Modelo Adhoc y su Tablero de Métricas e Indicadores para Evaluar el Grado de Inteligencia de una Ciudad," in Jornadas de Ciencia y Tecnología 2018.

[24] C. Salgado et al., "Los Procesos de Negocio en las Smart City: Un nuevo Paradigma," in XX Workshop de Investigadores en Ciencias de la Computación, 2018: RedUNCI - UNNE.

[25] C. Salgado, M. Peralta, D. Riesco, L. Baigorria, and G. Montejano, "Un Framework para la Evaluación de Modelos Conceptuales de Procesos de Negocio," in XX WICC, 2018: RedUNCI - UNNE.

[26] P. Lombardi, S. Giordano, et al. "Modelling the smart city performance," Innovation, 2012.

[27] V. Albino, et al, "Smart cities: Definitions, dimensions, performance, and initiatives," J. U. Tech., 2015. 